Article

\title{
Sustainability and Natural Wines: An Exploratory Analysis on Consumers
}

\author{
Sara Fabbrizzi, Veronica Alampi Sottini, Maria Cipollaro * and Silvio Menghini
}

check for

updates

Citation: Fabbrizzi, S.; Alampi

Sottini, V.; Cipollaro, M.; Menghini, S Sustainability and Natural Wines: An Exploratory Analysis on Consumers. Sustainability 2021, 13, 7645. https:// doi.org/10.3390/su13147645

Academic Editor: Michael S. Carolan

Received: 3 June 2021

Accepted: 1 July 2021

Published: 8 July 2021

Publisher's Note: MDPI stays neutral with regard to jurisdictional claims in published maps and institutional affiliations.

Copyright: (C) 2021 by the authors. Licensee MDPI, Basel, Switzerland. This article is an open access article distributed under the terms and conditions of the Creative Commons Attribution (CC BY) license (https:/ / creativecommons.org/licenses/by/ $4.0 /)$.
Department of Agriculture, Food, Environment and Forestry (DAGRI), University of Florence, Piazzale delle Cascine 18, 50144 Florence, Italy; sara.fabbrizzi@unifi.it (S.F.); veronica.alampi@unifi.it (V.A.S.); silvio.menghini@unifi.it (S.M.)

* Correspondence: maria.cipollaro@unifi.it

\begin{abstract}
Wine production and consumption in Italy have a long tradition strongly linked to conventional products. Because of these market dynamics, the Italian wine industry has strongly increased the production of organic wines, as well as that of biodynamic and natural wines. Based on a qualitative survey of 210 wine consumers, this study explores the motivations which move the interests of consumers for the consumption of natural wine. The aim of the study is to verify if and how sustainability inspires demand. Considering the scarcity of studies on "natural wines" this research aims to provide a cognitive framework capable of giving a social representation of natural wine from the consumers' side, although not reaching a generalizable result.
\end{abstract}

Keywords: natural wines; sustainability; consumer preferences; terroir; content analysis; free listing; cognitive saliency index

\section{Introduction}

\subsection{Wine and Sustainability}

Sustainability related to wine production is gaining increasing interest among both consumers and producers. [1] The growing media debate about sustainability made consumers gradually aware of environmental and social issues, thus turning them into progressively important elements to be taken into account when purchasing wine. Since the 1990s, a new lifestyle focused on health and sustainability, the so-called Lifestyle of Health and Sustainability (LOHAS), has begun to spread globally. "LOHAS consumers" express a high level of environmental awareness and one of their goals is to prefer quality over quantity. They are willing to pay a premium price for intangible product attributes related to respect for environmental quality, human rights, and health [2,3]. This attitude has significantly influenced consumer choices in the agri-food sector, including wine in recent years [4]. Globally, a considerable number of consumers are increasingly interested in buying wines from sustainable production, giving this adjective a predominantly environmental connotation [5].

Wine is a highly differentiated product, and consumers follow a more complex decision-making process than for other food products during their purchasing choices [6]. The most relevant drivers for the consumer's choice of wine are many and can be summarized in the country of origin, region of production, grape variety, brand, price, vintage [7]. Alongside these "traditional attributes", sustainability-related elements are increasingly influencing consumer perceptions and preferences when choosing wine [8]. Sustainabilityrelated credence attributes which have the greatest impact on consumer choices for wine focus primarily on environmental aspects [1], leaving the economic and social aspects of sustainability in the background.

The evolutionary trends in consumer preferences have strongly influenced wine producers, leading them to consider sustainability as a progressively important key element in the competitive development of the sector [9]. In fact, producers can gain competitive 
advantages in adopting sustainable practices, especially in the environmental dimension, by being able to improve both the quality of the final products and their economic efficiency [10].

Several studies highlighted that the choices of companies that show particular attention to sustainability-related issues are not only driven by market trends but also by important personal motivations, such as passion and involvement in their work [10-12].

\subsection{Natural Wines}

Within the context of wine and sustainability, natural wines are an emblematic case, representing a small and rapidly developing niche [13].

There is no specific and official definition of "natural wine" [14], but in general, it can be said that a wine is natural when human intervention from the vineyard to the processing in the cellar is the minimum, making it a natural expression of a terroir and a grape variety. The philosophy of the producer of natural wines is to minimise the "human artifice" so that what nature can do is enhanced in the final product. According to this principle, a natural wine tends to enhance the agronomic phase (i.e., the production of the grapes) by reducing the role played by the processing in the cellar. Natural wines tend to enhance the production environment and the very ability of "human capital" to manage the entire production process and seasonal fluctuations, achieving a quality product without "hiding" behind heavy winemaking techniques capable of "correcting" and "compensating" for what "mother nature" grants. This characteristic is emphasised in the literature by some authors who refer to natural wines as authentic wines, made by producers who are custodians of their terroir [15]. Winemakers see natural wine production as the result of their passion for their territory and their philosophy of life. The social movement known as "terroirists" perceives wine as both a cultural and economic product, to which terroir offers a source of differentiation, linked to local history and heritage [13].

Therefore, natural winemaking is a return to "craft" winemaking methods, in which an attempt is made to recover the identity and character of the wine. Natural wines are linked to a specific territory, which means moving away from the flattening of production in recent years. The craft dimension is also reflected in the size of the wineries themselves, as several associations only admit producers who cultivate vines on an area of no more than 15 hectares.

The issue of natural wines is as controversial as ever. On the one hand, there is still a lack of awareness among consumers of natural wine, even among organic wine consumers, who are more sensitive to health issues than to sustainability [16]. On the other hand, there is a lack of legislation and regulation on the subject, a fact widely emphasised by the producers of natural wines themselves [14], who, however, are not interested in the introduction of production regulations, considering the latter almost superfluous or even a limitation. This is the case in some production contexts, such as Italian DOC productions which, by providing for very stringent process and product conformity, set constraints that natural wine producers see as a heavy limitation on what they intend to accomplish through their activity, weakening the expression of terroir.

These issues, which are of fundamental importance for natural wines, are now affecting the entire Italian wine production system. The production specifications, although the architects of a long and extraordinary success, are urged to be more flexible by increasingly broad and dynamic markets in which it is necessary to safeguard the specificity of the denomination with the dynamics of demand, allowing each winery to appropriately differentiate itself [17].

A clear definition of "natural wine" is generally lacking at the European level [18]: the winegrowers' associations operating in different countries have their own "vision" of natural wine $[18,19]$. The various winegrowers' associations that support natural wines in Italy, such as VinNatur, ViniVeri, Triple "A", "Sans Aucun Intrant Ni Sulfite" (S.A.I.N.S.), Association des Vins Naturels (A.V.N.), while respecting the originality of individual producers, have internal rules that seek to guide the activities of their members. However, 
the rules that these associations have set for themselves often do not coincide with each other, thus not contributing effectively to the precise definition of the product.

For instance, the Charter of the French association S.A.I.N.S. states:

"[ ... ] The transformation of grape juice into wine occurs in a natural way and only with the help of yeasts and native bacteria." It also states: "[ . . ] Sulphites and other oenological inputs, in 100\% of his wine growing activity, are therefore not used. [ .. . ]" [20]. The Spanish Producers' Association AVN, provides the following definition of "natural wine": "Natural wine is wine made with natural grapes, without adding or removing anything from that grape. The result is a faithful reflection of the land from which the wine is produced" [21]. This description of natural wine reflects a point of view of the Spanish Association strongly oriented towards an environmentally friendly and natural production [13].

For both these associations, the use of sulfites is totally excluded, whereas the VinNature association allows the addition of up to $50 \mathrm{mg} / \mathrm{L}$ for white wines and $30 \mathrm{mg} / \mathrm{L}$ for red wines, while other associations, such as S.A.I.N.S. and A.V.N., do not allow their use.

The unclear picture thus created can further confuse consumers, who are reticent about natural wines, due both to a lack of knowledge about the product and to the absence of common production rules regulated by law. Thus, consumers show confusion between natural, organic and biodynamic wines [13,22].

Despite the confusion generated by the absence of precise certification rules and ambiguous labelling (Figure 1), most regular consumers of natural wines and the producers themselves are not interested in the presence of specifications on the subject. They share the idea that the specific craft, cultural and morphological specificities typical of a given territory cannot be translated into a regulated method.
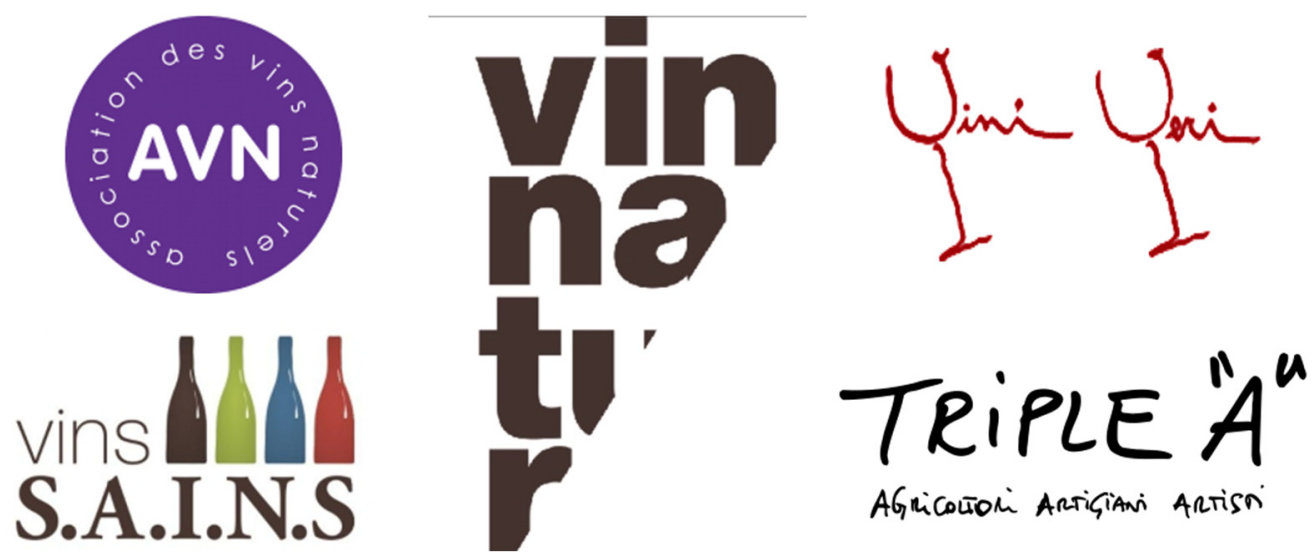

Figure 1. Wine labels of the major natural wine Associations in Italy.

The absence and, to some extent, the refusal to produce according to the dictates of a specification set the conditions and at the same time offer the opportunity of creating a relationship of trust and direct knowledge between the consumer of natural wines and the producer. The direct dialogue with the producer, or that mediated by shops specialising in the sale of these wines, replaces the security of certification with the personal guarantees of the person (producer or dealer) who directly sells the product. Direct and assisted sales, which characterise the natural wine trade, are not only a means of offering a personal guarantee, but also an ideal model for combining sales functions with those of customer education. They make it possible to guide the customer in understanding the characteristics of the product and, consequently, to increase the degree of satisfaction derived from its consumption. 


\subsection{The Context}

Unfortunately, no official statistics are available on biodynamic and natural wine production, but only reports issued by associations and, as such, limited to the data of their members. The only reliable official data refer to organic production. However, even if indirectly, some data on the growth dynamics of organic wine production and consumption indicate that sustainability issues have definitely penetrated this production sector as well.

Organic production in Italy accounts for approximately $6 \%$ of the total number of companies in the Italian agricultural sector, involving 58,697 agricultural producers and 11,843 producer-processors. In the organic sector, there are 9576 processors and 527 importers operating [23,24].

At the agricultural level, organic production covers an area of 1.99 million hectares [24], equal to $16 \%$ of the entire national UAA (Utilized Agricultural Area). Of this area, $5.5 \%$ $(109,424$ hectares, 25,599 of which in conversion) is dedicated to organic vine production, largely devoted to wine grape production and only marginally to table grape production. The growth of such production is significant, especially in the wine sector. In 2009 [25], the area under organic cultivation in Italy covered 1.1 million hectares with 43,614 of which under vine cultivation: therefore, in ten years, there was a general increase of $80 \%$ in the area dedicated to organic production and a $151 \%$ increase in vine cultivation. These data show how the wine sector, after years of little involvement in organic production, has now discovered the opportunities to respond to a demand that is increasingly oriented towards more responsible and healthy forms of consumption.

The significant increases in the supply of organic wines are linked to an equally clear growth in the national demand for organic products, which, in 2020, accounted for $4 \%$ of the total turnover of the national agro-food industry. On the consumption level as well, there are no official sources, but only partial information, deriving often from market surveys conducted by distributors. Through an informative report, an Italian non-store retail distributor leader [26], states that in four years (2016-2019) the share of biodynamic, natural and vegan wines marketed through its sales channels has basically doubled, from $8 \%$ of total turnover in 2015 to $15 \%$ in 2018 .

\section{Materials and Methods}

This work aimed to study the consumer perception of "natural wines" through the development and application of an online questionnaire survey $[27,28]$. Both quantitative and qualitative analysis techniques were used to analyze the collected data.

The questionnaire was developed and administered online in April 2019. The questionnaire was carried out on a representative sample of 300 people with the use of an online survey designed according to the Computer Assisted Web Interview (CAWI) technique. CAWI is a technique for collecting information in opinion research, as the respondent is asked to complete the questionnaire following a script provided on a website.

This technique is one of the most widely applied in marketing studies.

A "snowball" sampling technique was used to obtain the sample. The choice of this sampling technique, in combination with the data collection methodology, was based on the experimental design of the research (not probabilistic) and on the need to maintain the characteristics of the original sample as much as possible.

In fact, the CAWI technique generally tends to favor people from specific generational cohorts. The under-coverage of higher age groups, which represents one of the main limitations attributable to this interview method, was therefore considered acceptable, according to the exploratory approach adopted and because the survey aimed to investigate the phenomenon among the new generations.

Generally speaking, Generation Y (Millennials) and Generation Z seem to be more likely to identify, compared to others generations, in the guiding values of the LOHAS consumers, and in particular in the principles of sustainability [27]. As far as the wine market is concerned, Millennials are willing to pay a premium price for natural wines [14]. 
The questionnaire examined the general socio-demographic characteristics of the respondents and their main behavioural patterns relating to both their general eating style and specific product involvement in wine consumption.

In order to collect this information, the questionnaire contained both open-ended and close-ended questions. Information on the socio-demographic characteristics of the sample and the consumption habits of food and wine products was analysed by calculating simple descriptive statistics. The responses to the open-ended question, however, allowed us to gain insight into the food category "natural wines".

With regard to the specific category of natural wines, the questionnaire examined it according to the free listing technique, which consists of asking respondents to list the words characterising a certain topic $[22,28,29]$. In our research case, respondents were asked to list the main characteristics they associate with a natural wine.

Once this semantic field had been identified, the synonyms present were identified and brought together in a single category. Then, the cognitive saliency index was calculated. This index shows how this domain is perceived by the group of respondents according to the psychological salience parameter [30].

Psychological salience is given by the relevance of the words elicited, in terms of order and frequency. Synonyms and similar words were grouped into a single characteristic and systematised in a matrix, whose rows were made up of the different characteristics while the columns of the subjects. Characteristics indicated by less than $10 \%$ of the respondents were removed from the matrix [31], resulting in the identification of 15 final relevant characteristics. In the matrix, the intersection between the two parameters (characteristics) and subjects) the position in which the characteristic was expressed by the respondent is recorded. Thanks to the matrix, the cognitive saliency index (CSI) was calculated for each $j$ th characteristic, by the following formula:

$$
C S I_{j}=F_{j} / N^{*} A P_{j}
$$

where

$F_{j}$ is the number of subjects who mentioned the characteristic $j$,

$N$ is the total number of subjects,

$A p_{j}$ is the average of the positions of the characteristic $j$.

$J: t h$ characteristic

The CSI is normed to vary between 0 and 1 . If all subjects have named a term $\left(F_{j}=N\right)$ and the mean position of that characteristic is 1 , then the salience (CSI) is also 1 for that characteristic. The adoption of a cognitive salience index allows the comparison of results between different investigations, as it does not depend on the length of the individual lists [30].

\section{Results and Discussion}

Of the 300 questionnaires sent out, 210 useful responses were selected (70\%). Because of the CAWI methodology adopted, the respondents were all under 50 years old (Table 1). The questionnaires addressed to older subjects were, in most cases, partially completed, so they could not be used for analyses.

In addition to examining the specific answers concerning consumers' perception of a natural wine, the questionnaire also investigated some general aspects of consumers' behaviour and their degree of involvement with wine. With regard to behavioural aspects, the general eating style and the role played by organic products were examined. In this respect, $92 \%$ of the respondents declared to be omnivorous, $7 \%$ vegetarian and the remaining $1 \%$ vegan. As for the extent to which organic products are included in their diets, only $5 \%$ of respondents stated they had never consumed organic food, while $63 \%$ declared they consume organic food sporadically, $22 \%$ fairly often and $10 \%$ often. Regarding product involvement, it was examined by asking respondents to express their degree of agreement 
(on a five-point Likert scale, from completely disagree to completely agree) with the following statements:

- "I have a great interest in wine",

- "I don't need special occasions to drink wine",

- "I select the wines I buy very carefully".

Table 1. Sample characteristics.

\begin{tabular}{cc}
\hline & $\%$ \\
\hline GENDER & \\
Female & 35.7 \\
Male & 64.3 \\
AGE & \\
$18-25$ & 36.7 \\
$26-30$ & 18.8 \\
$31-37$ & 21.3 \\
38-50 & 23.2 \\
EDUCATION & 8.3 \\
Without high school graduation & 57.3 \\
With high school graduation & 30.1 \\
University degree & 4.3 \\
Post-graduate university degree & 28.5 \\
PROFESSIONAL POSITION & 44.0 \\
Student & 17.4 \\
Employee & 10.1 \\
Entrepreneur-freelancer &
\end{tabular}

By combining the answers given to the three statements, it was possible to distribute the respondents into three groups characterised by a different degree of involvement which could range from a "high involvement" category, which includes subjects who do not need special occasions to consume wine and who have a great interest in the wines they buy, choosing them with care, to the "low involvement" category, which includes subjects who consume wine only sporadically and who have little interest in the wine they buy, choosing it with little care (Figure 2):

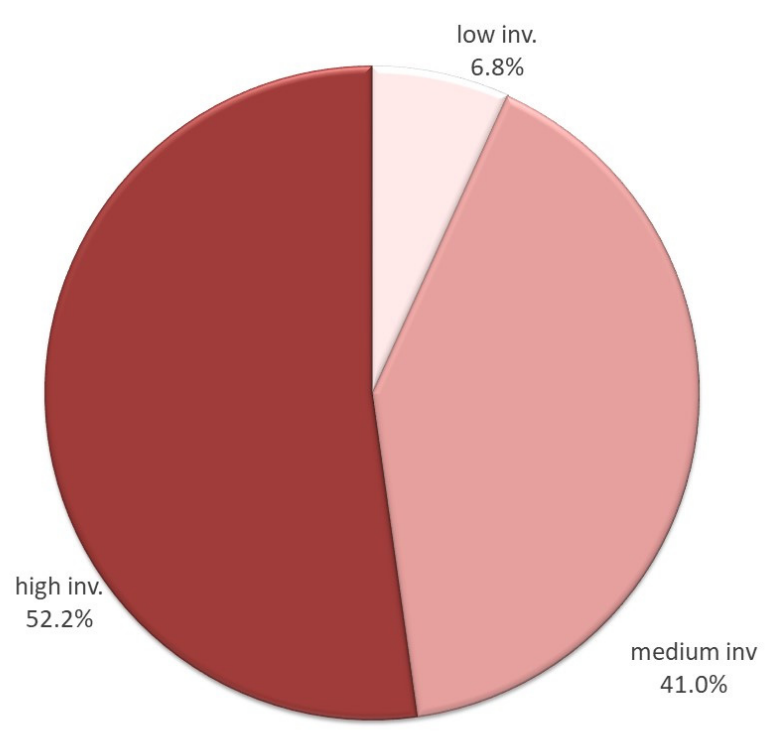

Figure 2. Product involvement. 
The analysis shows a high involvement between the interviewees and wine, confirming the role that this product still plays in Italy's food and social life.

As opposed to this high involvement, knowledge and consumption of natural wines are low: $53.6 \%$ of those interviewed state that they are not familiar with this product, while in the remaining $41.5 \%$, there is a significant number of interviewees who, although familiar with the product, do not consume it $(17.9 \%)$, or consume it very rarely $(23.7 \%)$. Only $4.8 \%$ of the respondents stated that they consume it regularly (Figure 3 ):

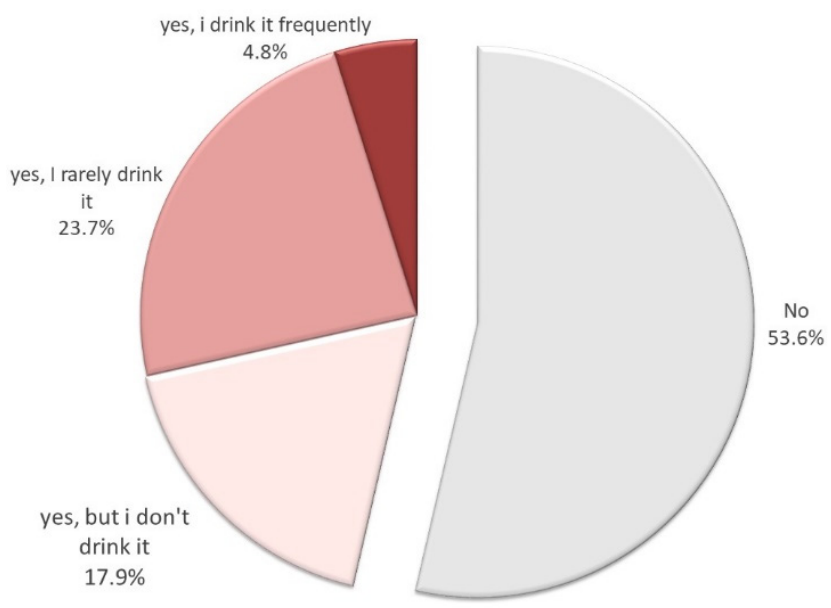

Figure 3. Knowledge of natural wine.

The correlation between product involvement and level of knowledge of natural wines is significant (Table 2):

Table 2. Product involvement and knowledge of natural wines.

\begin{tabular}{|c|c|c|c|c|c|c|}
\hline \multicolumn{7}{|c|}{ Knowlege of Natural Wines } \\
\hline $\begin{array}{c}\text { Product } \\
\text { Involvement }\end{array}$ & $\begin{array}{l}\text { Unknown } \\
\text { Product }\end{array}$ & $\begin{array}{l}\text { Product Known } \\
\text { but Never Cons }\end{array}$ & $\begin{array}{c}\text { Rare } \\
\text { Consumption }\end{array}$ & $\begin{array}{c}\text { Frequent } \\
\text { Consumption }\end{array}$ & Tot & $\%$ \\
\hline Low & 14 & & 1 & & 15 & $7.2 \%$ \\
\hline Medium & 61 & 11 & 15 & & 87 & $41.4 \%$ \\
\hline High & 38 & 27 & 33 & 10 & 108 & $51.4 \%$ \\
\hline Tot & 113 & 38 & 49 & 10 & 210 & $100.0 \%$ \\
\hline$\%$ & $53.8 \%$ & $18.1 \%$ & $23.3 \%$ & $4.8 \%$ & $100.0 \%$ & \\
\hline
\end{tabular}

Focusing on the $4.8 \%$ of respondents who consume natural wines regularly, i.e., several times a month, we observe that they are all characterised by a high level of involvement in wine and an above-average frequency of consumption of organic products. Through the other questions asked, it is possible to draw a profile of these consumers. When buying food products, they pay particular attention to raw materials from organic production and are particularly sensitive to issues of corporate social responsibility, especially with regard to fair trade. This consumer niche demonstrates a vision of sustainability that goes beyond environmental issues alone, showing interest in social issues as well. The purchase of wines for indoor consumption is mainly made in wine shops, while outdoor consumption takes place largely in specialized wine shops which often also offer restaurant service with organic products. The key information guiding their choices is mainly linked to direct knowledge of the producer and advice from the manager (both in the wine shop and on the premises).

Comparing the high degree of involvement for wine (Table 2) with the low levels of knowledge and consumption of natural wines, it is clear that the demand for such products 
still has a high potential for growth, especially nowadays in the light of the great increase in demand for sustainable products.

Because of the general lack of knowledge about natural wines, confirmed in the survey by $53.8 \%$ of respondents who said they were not familiar with them, the questionnaire proposed the following definition before the questions concerning consumers' perception of these products:

"There is no single definition for a natural wine. It is certainly a wine whose grapes must come from organic farming, from owned vineyards and must be vinified by spontaneous fermentation. A natural wine requires as little intervention as possible, both in the vineyard and in the cellar. It also requires the absence of chemical additives and manipulation. Only sulphur dioxide is generally permitted within a maximum limit of 30 or $50 \mathrm{mg} / \mathrm{lt} . "$

After providing a definition of natural wine, the answers were collected and then processed according to the salience index.

On the basis of this analysis, all the subjects interviewed showed a perception of natural wines that are mainly linked to characteristics directly associated with the terms of the Lifestyle of Health and Sustainability mentioned above: in fact, the terms "healthy", "genuine" and "natural" stand out in the answers collected and processed (Figure 4, Table 3).

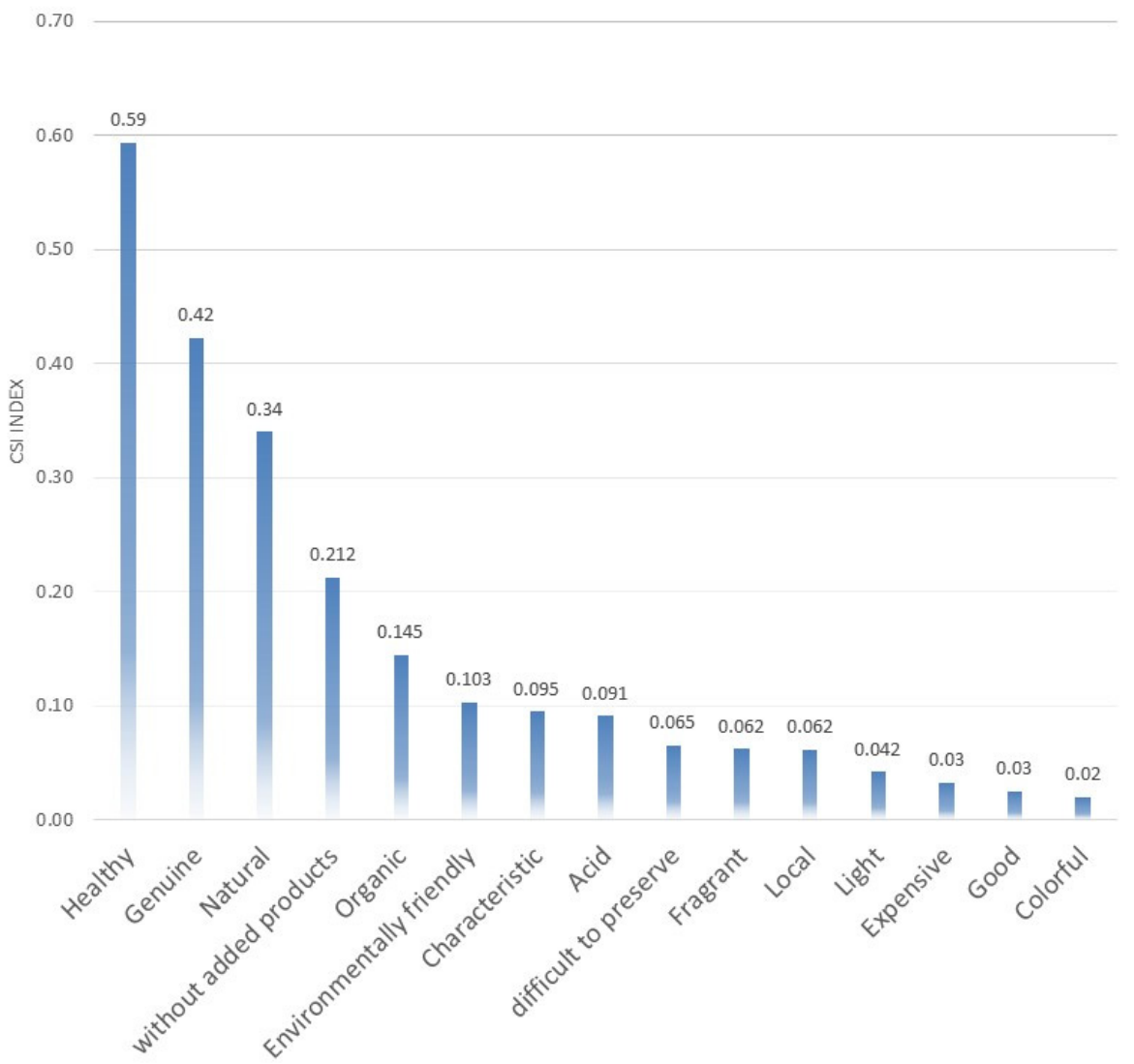

Figure 4. Cognitive saliency index of characteristics identified by the free listing technique.

The healthy category shows the highest salience index, mainly due to the high frequency with which it was mentioned. Among the characteristics mentioned by the interviewees, there are also elements linked to the product's specificity and uniqueness, its deep connection with the territory and its aroma. However, in the consumer's imagination regarding natural wines, some negative attributes, such as being acidic, unsuitable for storage and expensive, are listed. It is important to bear in mind that the lesser relevance of these negative items in the consumer's cognitive sphere is not due to the low frequency 
with which they are mentioned, but mainly to the order in which they are made explicit: these aspects are recurrent but not relevant compared to positive peculiarities considered far more important, or even partly tolerated, as an implicit expression of a natural wine. In conclusion, the results show that there are several consumers who have a negative perception of natural wines, which then results in a low willingness to buy such products.

Table 3. Recurring terms in the free listing for the different characteristics.

\begin{tabular}{ccc}
\hline Characteristics & $\begin{array}{c}\text { Examples of Relevant Words in the } \\
\text { Characteristics }\end{array}$ & Cognitive Saliency Index \\
\hline Healthy & good for health, wholesome, good for & you \\
Genuine & real, authentic, spontaneous & 0.59 \\
Naturale & pure, without human intervention, in line & 0.42 \\
with the cycles of nature & 0.34 \\
Without added & preservative-free, sulphite-free, & \\
products & chemical-free & 0.212 \\
Organic & Organic & 0.145 \\
Environmentally & sustainable, ecological, non-polluting & 0.103 \\
friendly & typical, peculiar, unique & 0.095 \\
Distincitve & harsh, not attractive & 0.091 \\
Acid & not storable, perishable & 0.065 \\
Poorly preservable & aromatic, fruity, floral & 0.062 \\
Fragrant & terroir, native, territorial & 0.062 \\
Local & fresh, digestible, mild & 0.042 \\
Light & high price, elite & 0.03 \\
Expensive & pleasant, tasty, enjoyable & 0.03 \\
Good & dark wine, deep red & 0.02 \\
Coloured &
\end{tabular}

Although the research presented here is about the analysis of consumers of natural wines, it is appropriate to report some first results of another research that the same team is conducting in order to identify the motivations that guide producers of the sector to operate in this particular niche. This analysis was conducted on 25 respondents with face-to-face interviews, using a semi-structured questionnaire including open-ended questions. The questionnaires were collected at a trade fair event attended by all small producers (with an area under vines not exceeding 15 hectares). The information collected from the interviews was analysed by adopting the method of content analysis (Table 4) (Frequently used in studies and research on consumer behaviour and communication content, content analysis offers a methodological approach to systematically measure the content of any text [32]. In this research, the methodology was implemented to the interviews carried out among producers, as it allowed the many words recorded in the open answers to be synthesized into a reduced number of conceptual categories [33]. The word reduction was possible through coding procedures that transformed the raw data, resulting from the answers respondents gave to open ended questions, through selecting and focusing processes [34]. The analysis of the text was carried out through the ex-post structuring of conceptual categories, according to a qualitative rather than a quantitative lexicometric approach. The coding reliability was verified by a second researcher who reported a very high level of agreement, with an "inter-coder reliability" of over 0.8 [35]).

Of the producers, $92 \%$ declared that natural wine production is an expression of personal passion and not a choice determined by the fashion of the moment. This finding confirms what has previously been noted in the literature [11] regarding the relevance of the producers' internal motivations, such as passion and involvement, and of their sensitivity to undertaking a sustainable production path, rather than one focused on profit maximisation. Motivations linked in various ways to "tradition" are also very frequent ( $72 \%$ of the interviewed). Tradition is seen both as the continuation of an activity that has already been carried out for some time, and as a choice of reconversion undertaken to 
recover more sustainable production methods typical of a technologically less advanced past. Among the producers interviewed, the motivation linked to "terroir" also emerges significantly (56\%). Producers believe that a natural wine is a product intimately linked to the history and culture of the place and the territory from which the grapes come. Respect for the environment and human health emerges explicitly among the other motivations mentioned by producers.

Table 4. Motivational categories of natural wine producers.

\begin{tabular}{|c|c|c|c|}
\hline Categories & $n$. & $\%$ & Examples of the Most Relevant Sentences in the Categories \\
\hline Passion & 23 & $92 \%$ & $\begin{array}{l}\text { "it's not a fashion choice, we believe in it and we love what we } \\
\text { do"; "if I believe in what I do, the vineyard pays back" }\end{array}$ \\
\hline Tradition & 18 & $72 \%$ & $\begin{array}{l}\text { "to continue the techniques of my grandparents without } \\
\text { forcing them"; "a link with the past, with my roots" }\end{array}$ \\
\hline Terroir & 14 & $56 \%$ & $\begin{array}{c}\text { "each wine has its own history, it is a piece of our territory"; "it } \\
\text { is the result of the soil, the air, the local techniques handed } \\
\text { down in the decades, the culture" }\end{array}$ \\
\hline Environment & 8 & $32 \%$ & $\begin{array}{l}\text { "our methods preserve the environment, respect the territory"; } \\
\text { "we preserve the soil, we are in tune with nature" }\end{array}$ \\
\hline Health & 5 & $20 \%$ & $\begin{array}{l}\text { "I want to promote a safe, healthy, non-harmful product"; "the } \\
\text { consumer is increasingly aware of the importance of health: } \\
\text { our product meets this need" }\end{array}$ \\
\hline
\end{tabular}

\section{Conclusions}

This research aims to contribute to the almost unexplored field of natural wines studies. In particular, it aims to better outline the market segment of natural wine and to better define its positioning in relation to other conventional and organic products. The exploration of the conceptual categories that consumers have in relation to natural wine constitutes a solid informative basis for a social representation of the product. The results of this research confirm the findings of other studies conducted during the same period of our research and on the same topics, although with different methodologies [36].

More in detail, the perception that consumers have of natural wines, which emerged through the salience index, highlights elements of value and criticality that represent a useful cognitive desk tool for the definition of competitive positioning strategies for the companies involved in the sector. The producer of natural wines shall try to leverage the attributes of value that have greater weight according to the cognitive saliency index, while limiting the weight of the negative aspects that consumers still associate with these products. Producers should therefore act both on the functional characteristics of the product and on its reputation, eradicating from the collective imagination a qualitative perception of organic and natural wines that still suffer from prejudices linked to a not "faultless" production past.

The enhancement of functional characteristics requires further technical improvements, while on reputation it is necessary to act with adequate marketing strategies able to reach and interact with consumers who are not very familiar with natural wines. In the present research, this aspect is confirmed by the fact that the negative characteristics examined by the CSI terms recur more often in consumers with a lower degree of involvement in the product and a rare consumption.

The need to work on these two aspects contemporaneously is important to improve some important characteristics of the natural product that do not fit certain quality standards for both consumers and experts in the sector. Even if the aim is not to define as specific peculiarities certain defects that can be found in a natural wine (not only in the product as such but also in terms of shelf life), it is important to properly educate the consumer on certain characteristics that distinguish a natural wine, which deserves to be judged according to very specific qualitative reference criteria.

According to the information framework that the research partly provides, producers should develop an appropriate communication message that, as the literature claims [37], 
will be all the more effective the more in line with the language of the consumer himself. As can be seen from the results of this research, the attributes that are relevant to the consumer clearly emerge and represent the key elements to focus on, as they identify a product, wine, no longer simply seen as a good destined to satisfy a specific need, but also as a tool that can contribute to the realisation of a healthy and sustainable lifestyle.

At the same time it should be noted that the negative attributes that emerged from the study, such as high cost, being acidic, unsuitable for storage and expensive, are considered less important by the respondents and however tolerated, as a peculiarity of a "natural wine".

As regards the motivations that drive producers of natural wines, the survey shows that they are entirely consistent and, in many ways, strongly synergic with consumer expectations. In this regard, it is important to emphasise that the motivations of the producers, which the study showed to be at the basis of the company's mission and objectives, do not stem from particular and sophisticated market analyses, but represent the spontaneous and personal expression of the aspirations of each entrepreneur. These findings indicate a solid and positive matching point between supply and demand, in which each stakeholder does not play a strategic role but expresses his/her own deep motivations. However, even if all this could be seen as a strength, it could also represent a limitation to the future growth of the natural wine market if we consider that in many situations "[ ... ] The difficulty is not to understand new ideas, but to escape old ideas [... ]" [38] (p. XVIII), especially when these ideas are the fundamental motivations in one's personal life and profession. Similarly, the absence of a single, clear definition of natural wine and of accurate indications on authorised production practices could become an increasingly evident weakness as the natural wine market grows beyond the boundaries of the niche market in which it has grown so far. The future development of sustainable wines needs important eco-innovations that require specific regulations and an accurate concordance with the market's ethical preferences [39]. The biggest challenge for producers of natural wines will be to understand whether growing and breaking out of the niche in which they have grown so far means evolving without changing their original nature or becoming something different.

Because of the explorative nature of this paper, the results of this research are not generalizable to the entire population of consumers of wine and natural wine in Italy. If this aspect represents a limitation of this paper. However, this work provides an important contribution, by proposing a cognitive framework able to give a social representation of natural wine by consumers. In scientific literature, it is highlighted [14] how further research is needed in this field. Moreover, it should be noted that the use of a non-probabilistic approach is, at least in part, justified not only by the lack of knowledge about natural wine, but by the lack of knowledge of the market segment of natural wines itself. The knowledge of the socio-demographic characteristics of natural wine consumers is fundamental for the development of new analyses, which can also use conclusive methodological approaches (probabilistic). This work is intended to provide initial information in this regard as well.

Author Contributions: Conceptualization, S.F., V.A.S., M.C. and S.M.; methodology, S.F. and S.M.; software, S.F. and S.M.; validation, S.F., V.A.S., M.C. and S.M.; formal analysis, S.F., V.A.S., M.C. and S.M.; investigation, S.F.; resources, S.F., V.A.S., M.C. and S.M.; data curation, M.C.; writing-original draft preparation, V.A.S.; writing-review and editing, V.A.S.; visualization, S.F., V.A.S., M.C. and S.M.; supervision, S.M.; project administration, S.F. and S.M. All authors have read and agreed to the published version of the manuscript.

Funding: This research was not funded by any agencies in the public, commercial, or not-forprofit sectors.

Institutional Review Board Statement: Not applicable.

Informed Consent Statement: Not applicable.

Data Availability Statement: Data are available with authors upon request.

Conflicts of Interest: The authors declare no conflict of interest. 


\section{References}

1. Szolnoki, G. A cross-national comparison of sustainability in the wine industry. J. Clean. Prod. 2013, 53, 243-251. [CrossRef]

2. D'Amico, M.; Di Vita, G.; Monaco, L. Exploring environmental consciousness and consumer preferences for organic wines without sulfites. J. Clean. Prod. 2016, 120, 64-71. [CrossRef]

3. Pícha, K.; Navrátil, J. The factors of Lifestyle of Health and Sustainability influencing pro-environmental buying behaviour. J. Clean. Prod. 2019, 234, 233-241. [CrossRef]

4. Forbes, S.L.; Cohen, D.A.; Cullen, R.; Wratten, S.D.; Fountain, J. Consumer attitudes regarding environmentally sustainable wine: An exploratory study of the New Zealand marketplace. J. Clean. Prod. 2009, 17, 1195-1199. [CrossRef]

5. Schäufele, I.; Hamm, U. Consumers' perceptions, preferences and willingness-to-pay for wine with sustainability characteristics: A review. J. Clean. Prod. 2017, 147, 379-394. [CrossRef]

6. Lockshin, L.; Hall, J. Consumer Purchasing Behaviour for Wine: What We Know and Where We Are Going. Ph.D. Thesis, University of South Australia, Wine Marketing Research Group, Adelaide, Australia, October 2003.

7. Drennan, J.; Bianchi, C.; Cacho-Elizondo, S.; Louriero, S.; Guibert, N.; Proud, W. Examining the role of wine brand love on brand loyalty: A multi-country comparison. Int. J. Hosp. Manag. 2015, 49, 47-55. [CrossRef]

8. Klohr, B.; Fleuchaus, R.; Theuvsen, L. Sustainability: Implementation programs and communication in the leading wine producing countries. In Proceedings of the 7th International Conference of the Academy of Wine Business Research (AWBR), St. Catharines, ON, Canada, 12-15 June 2013; Volume 1215.

9. Valenzuela, L.; Maturana, S. Designing a three-dimensional performance measurement system (SMD3D) for the wine industry: A Chilean example. Agr. Syst. 2016, 142, 112-121. [CrossRef]

10. Flores, S.S. What is sustainability in the wine world? A cross-country analysis of wine sustainability frameworks. J. Clean. Prod. 2018, 172, 2301-2312. [CrossRef]

11. Gabzdylova, B.; Raffensperger, J.F.; Castka, P. Sustainability in the New Zealand wine industry: Drivers, stakeholders and practices. J. Clean. Pro. 2009, 17, 992-998. [CrossRef]

12. Giacomarra, M.; Galati, A.; Crescimanno, M.; Tinervia, S. The integration of quality and safety concerns in the wine industry: The role of third-party voluntary certifications. J. Clean. Pro. 2016, 112, 267-274. [CrossRef]

13. González, A.P.; Dans, P.E. The 'terroirist' social movement: The reawakening of wine culture in Spain. J. Rural. Stud. 2018, 61, 184-196. [CrossRef]

14. Galati, A.; Schifani, G.; Crescimanno, M.; Migliore, G. "Natural wine" consumers and interest in label information: An analysis of willingness to pay in a new Italian wine market segment. J. Clean. Pro. 2019, 227, 405-413. [CrossRef]

15. Goode, J.; Harrop, S. Authentic Wine Toward Natural and Sustainable Winemaking, 1st ed.; University of California Press: Berkeley, CA, USA, 2011.

16. Moscovici, D.; Reed, A. Comparing wine sustainability certifications around the world: History, status and opportunity. J. Wine Res. 2018, 29, 1-25. [CrossRef]

17. Menghini, S. Designations of origin and organic wines in Italy: Standardisation and differentiation in market dynamics. Wine Econ. Policy 2018, 7, 85-87. [CrossRef]

18. González, P.A.; Parga-Dans, E. Natural wine: Do consumers know what it is, and how natural it really is? J. Clean. Prod. 2020, 251, 119635. [CrossRef]

19. Teil, G. No such thing as terroir? Objectivities and the regimes of existence of objects. Sci. Technol. Hum. Values 2012, 37, 478-505. [CrossRef]

20. Les Vins, S.A.I.N.S. Available online: https://vins-sains.org/category/La-charte/Fran\%C3\%A7ais (accessed on 28 June 2021).

21. Qué Es Vino Natural. Available online: http:/ / www.vinosnaturales.org/vino-natural/ (accessed on 28 June 2021 ).

22. Ginon, E.; Ares, G.; Issanchou, S.; dos Santos Laboissière, L.H.E.; Deliza, R. Identifying motives underlying wine purchase decisions: Results from an exploratory free listing task with Burgundy wine consumers. Food Res. Int. 2014, 62, 860-867. [CrossRef]

23. ISTAT. ISTAT WORKING PAPERS. Un'analisi Integrata Delle Principali Fonti Statistiche e Amministrativ Sulla Produzione Di Vino in Italia. 2020. Available online: https:/ / www.istat.it/it/files/2021/01/IWP_8-2020.pdf (accessed on 5 July 2021).

24. SINAB. Bio in Cifre, Rapporto Annual. 2020. Available online: www.sinab.it (accessed on 28 June 2021).

25. INEA. L'agricoltura italiana conta 2010, Il Sole 24 Ore-Agrisole. 2010. Available online: http://dspace.inea.it/handle/inea/304 (accessed on 28 June 2021).

26. HORECAnews. Tannico si Prepara al Vinitaly con Una Ricerca sul Consumo dei Vini. Available online: https://www.horecanews. it/tannico-si-prepara-al-vinitaly-con-una-ricerca-sul-consumo-dei-vini/ (accessed on 5 July 2021).

27. Baybars, M.; Ventura, K. Understanding new consumers through the lens of a promising market segment: Lohas. In New Communication Approaches in the Digitalized World; Cambridge Scholars Publishing: Newcastle upon Tyne, UK, 2020 ; p. 468.

28. Barone, B.; Nogueira, R.M.; Behrens, J.H. Sustainable diet from the urban Brazilian consumer perspective. Food Rev. Int. 2019, 124, 206-212. [CrossRef]

29. Libertino, L.; Ferraris, D.; Osornio, M.L.; Hough, G. Analysis of data from a free-listing study of menus by different income-level populations. Food Qual. Prefer. 2012, 24, 269-275. [CrossRef]

30. Sutrop, U. List task and a cognitive salience index. Field Methods 2001, 13, 263-276. [CrossRef] 
31. Hough, G.; Ferraris, D. Free listing: A method to gain initial insight of a food category. Food Qual. Prefer. 2010, $21,295-301$. [CrossRef]

32. Duriau, V.J.; Reger, R.K.; Pfarrer, M.D. A content analysis of the content analysis literature in organizational studies: Research themes, data sources, and methodological refinements. Organ Res. Methods 2007, 10, 5-34. [CrossRef]

33. Krippendorff, K. Content Analysis: An Introduction to its Methodology; Sage Publications: Thousand Oaks, CA, USA, 2004; ISBN 978-0-7619-1545-4.

34. Miles, M.B.; Huberman, A.M. Qualitative Data Analysis: An Expanded Sourcebook; Sage Publications: Thousand Oaks, CA, USA, 1994; ISBN 0-8039-5540-5.

35. Campbell, J.L.; Quincy, C.; Osserman, J.; Pedersen, O.K. Coding in-depth semistructured interviews: Problems of unitization and intercoder reliability and agreement. Sociol. Methods Res. 2013, 42, 294-320. [CrossRef]

36. Urdapilleta, I.; Demarchi, S.; Parr, W.V. Influence of culture on social representation of wines produced by various methods: Natural, organic and conventional. Food Qual. Prefer. 2021, 87, 104034. [CrossRef]

37. Bilman, E.M.; Van Trijp, J.C.M.; Renes, R.J. Consumer perceptions of satiety-related snack food decision making. Appetite 2010, 55, 639. [CrossRef]

38. Keynes, J.M. The Difficulty Is Not to Understand New Ideas, but to Escape Old Ideas; Independently published; 2020; ISBN 979-8642475188.

39. Frigon, A.; Doloreux, D.; Shearmur, R. Drivers of eco-innovation and conventional innovation in the Canadian wine industry. J. Clean. Prod. 2020, 275, 124115. [CrossRef] 